\title{
R. Keith Sawyer ${ }^{1}$
}

\section{An Interview by Mark Laver}

Keith Sawyer: I've been involved with the ICASP grant from the beginning; I was invited to be an external consultant and it's very exciting to have this international project based here at the University of Guelph. I was at a conference at the University of Cambridge this summer, and they have a big centre for performance studies centered at the University of Cambridge in the Faculty of Music, and they know of Guelph as the one other place internationally that is doing work in this area. So it's really putting Guelph on the map for the type of people who do the sort of work that I do.

I am a creativity researcher. I got interested in creativity originally because of my own experiences as a pianist. I started as a classical pianist, trained in the canon of the three B's: Bach, Beethoven, and Brahms, and I got very good at reading music from the page. And then, in high school, when I was about sixteen, I was invited to be the pianist for our jazz ensemble. Our high school had a very large jazz ensemble-eighteen-piece band-and I was known as a good pianist within the school, but when I was presented with the music I was surprised to see there was no notes on the page. It was a music staff, but with no notes on it. They had these chord symbols on top, and I actually had not known this is what I would be expected to do. So the bandleader came over, and he was a trumpet player, but he knew enough piano to show me a few basic voicings, and I basically had to teach myself and learn piano all over again. A fascinating experience, and then the rhythm section of the band wanted a four-piece combo, so I started playing around with them, and that's when I had my first taste of small-group jazz interaction where you have to improvise your part, at the same time as everybody else is improvising their parts. And the fascinating thing about it for me was the way that the parts would come together. So everybody would be capable of generating something that was a collectively generated product, but it wouldn't be planned, it wouldn't be organized, it wouldn't be scripted in advance. I call it emergent: from the bottom up.

And that's been my focus as I became a creativity researcher studying at University of Chicago with Mihaly Csikszentmihalyi. As I learned there, the tradition of psychology and studying creativity, in my view, had focused too much on the solitary individual-what goes on in the mind of the creative person and how they come up with ideas. Over the span of my whole life, I think about everything I see in terms of my experience as a jazz pianist; it's my guiding metaphor. So when I looked at creativity research, I thought this body of research was too focused on the individual, that if l'm looking at a jazz ensemble, this approach is not going to explain what's going on, looking at the mental structures of the mind of the pianist or bass player or whatever. Even if you get those down to four individual musicians and then you try to put them together, then the explanatory power of the psychological approach is limited. So I decided to dedicate my career to the study of group creativity, and I felt it needed a fundamentally different focus, so I studied improvisation of jazz ensembles, improvisation of theatre, collaborating groups in business organizations, collaborating groups in classrooms.

And what l've found when I look at what you need to have an innovative organization-and I'm not the first person to observe this (in fact, l'd say it's almost the accepted wisdom now)—is something that I see as fundamentally improvisational. These innovative organizations have figured out a way to capture, or bottle, improvisation, but in a way that's aligned with important business goals that help them accomplish important business outcomes. But what is characteristic of this kind of improvisation is that it is emergent; it's not planned from the top down-it's bottom up, it's unexpected. I also see in these organizations that are successful at capturing improvisation, they have some core characteristics. They have a certain kind of social networking, where there's a type of interaction and connection among members of the organization that quite often crosses organizational lines or functional boundaries. And there are many different explicit organizational strategies that these organizations use to help that be more likely. They have a culture in place that fosters a kind of deep collaboration, where it's not just lip service to collaboration, but they actually seek out collaboration-they want collaboration-they aren't directed to collaborate by management, but in many cases the collaborations form spontaneously as people just approach each other. There's a certain kind of a knowledge management-where the collective knowledge of the organization flows around in a certain sort of way through these types of social networks. At the same time, these types of organizations are very good at making external links outside the organization. What I see all of these things contributing to, again back to my psychology research experience, we know that people have better ideas when they're able to connect distant knowledge. We call it "remote association." And it's this remote association or distant combination that tends to result in a more surprising and new idea, and that's more likely to happen if you're having these kinds of interactions with people that are very different from you-different parts of the organization or even outside of the organization.

So, just to wrap up my introductory comments, what I think about these days is this challenge: how do you manage an organization so that this kind of improvisational collaboration can be successful? You can't have an organization be exactly like a jazz ensemble, and certainly not exactly like a free jazz ensemble, because it would be a chaotic 
mess from the organizational perspective. You wouldn't accomplish organizational goals, you wouldn't make a profit, you would go out of business. There is quite a bit of research showing there is a sweet spot: there is a way to channel this kind of emergent, bottom-up improvisation, but in the context of an organization. It takes a certain kind of leadership style, a way of enacting leadership-sometimes it's distributed leadership. It takes a very special kind of culture and set of norms to be in place, where it becomes second nature for people to collaborate in this way.

For example, there's a certain way that incentives are designed in these organizations that is in some cases counterintuitive. For example, you don't reward people who have good ideas, which sounds puzzling to a lot of human resource managers. "Well, if we want innovation, we should reward people who have good ideas!" Well, the successful, innovative organizations don't do that, because what that does is it makes people think about their own ideas, it makes them possessive, it blocks collaboration. You don't find that kind of reward system in innovative organizations, but it's very hard to get the incentive system right to foster this kind of improvisational innovation. So, I thought I'd say a little bit about that, since we're in the context of a management conference, and maybe we'll talk more about the arts side for the interview portion.

Mark Laver: I'm very grateful for this opportunity, partly because Keith's research has been very central to my own research project as a postdoctoral fellow with the ICASP initiative. To get started, you've already hit on some of the issues, but I was wondering if you could speak generally to the relationship between creativity and improvisation. Is improvisation the necessary thing to foster creativity, or vice versa, or are they co-constituted in some way? What are your thoughts on that?

KS: Oh, it's a great question, I think, because I see everything through the lens of jazz improvisation, so, yeah, all creativity is improvisational. Maybe that would be my first reaction, but let me say more about why I think that's true. In improvisation, or collective, I should say, collaborative group improvisation, what you see-and this is true of jazz, or improvisational theatre, or collaboration in organizations-you see, when it's successful, each member of the group is contributing a very small bit. Say, it's one line of dialogue on the stage, or it's one phrase, or one little rhythmic bit on the cymbal if it's a jazz ensemble, but there are tiny little bits of new ideas that get contributed from moment to moment, very rapidly, and in a successful collaboration, there's a kind of deep listening so that the other performers hear those little bits, and then respond by contributing the next little bit. And that's the way improvisation unfolds, sort of moment to moment, in a highly contingent manner-what's here doesn't predict what's going to come five minutes later, because there are these combinatoric possibilities of the way things could unfold through those moment-to-moment contributions. So, here's why I think innovation in organizations is like that: it's because it's a myth that new products and successful innovations come from a really good idea in some brilliant person's mind. When you look at the history of invention, or the history of innovation in organizations, it's the same way. It's a lot of very small ideas that get contributed over time, in many cases, by different individuals, and it's the successful organizations that can create a context in which those ideas actually do build together over time, instead of just sitting on the table and not ever connecting to any other ideas.

So I do think that the history of invention and innovation is an improvisational flow over time. Writ large, it doesn't happen over one meeting; it might happen over six months, or two years. In some cases, when I study the nineteenth century, sometimes it's twelve, fourteen years that these innovations build over time. So, yeah, I guess I would say that innovation is always improvisational.

Creativity: I associate creativity with a more psychological process, of one person having an idea-so is that improvisational? The solitary idea is probably not improvisational, but the work process of a creative individual, even when they're alone, is improvisational, because there's an improvisational interaction with the materials, with the work as it's unfolding. It's very important that work be generated during the process and the creative process in that sense, I think it is improvisational. So I have written that even creativity researchers who are psychologists focused on the individual, they could still learn from looking at improvisation, because I think the individual process is improvisational over time.

ML: Right. And you've talked in other places about how that individual creative process can be fomented in different ways by having a collection of individuals operate within a collaborative framework-that each individual is hence going to be more creative in a collaborative sort of situation?

KS: Well, that's the challenge, because, I mean, we've all been in groups that were completely ineffective, right? Or where nothing got done, you would've been better off if you'd stayed at home by yourself. So that's the challenge: sometimes people think that because I study collaboration, I think collaboration is always better, but we all know it's not. So that's the challenge. How do you design, if you're in the management or leadership position, how do you design an organization so that the individual ideas of people do actually come together in a way that builds to something greater? It doesn't naturally happen. Culture has to be right and incentives have to be right. 
ML: Right. I should preface the next series of questions, actually, by mentioning that my own background is as an ethnomusicologist and cultural studies researcher. Management and economic theory is fairly new to me, and especially in these early stages, my cultural studies radar is going off all the time. And particularly in terms of issues around power, and basically the way that power underlies a lot of these collaborative relationships. In Explaining Creativity, one of your books, you mention that most social systems have vested interests in the status quo and true creative novelty is often perceived to be dangerous to those in positions of power. I was wondering if you could talk a little bit about some of the other systemic, socio-cultural obstacles that might prevent certain people from exercising creative, innovative agency, or participating in the innovate or collaborative projects? And maybe what kind of role an improvising business can play in addressing and ideally overcoming some of those obstacles.

KS: Right. That's a great question, and it's something I haven't really thought about before, but l'm thinking of two different ways I could kind of answer it. One is how do power dynamics play out within an organization, where, let's say, everyone is already privileged in some sense, because they're already all working at R.I.M., right? Or they're already working at Bang \& Olufsen. So I was at a conference in Copenhagen Business School this past May, and the focus was on evaluative practices in creative industries and these were all anthropologists who study business as anthropology. It's a new movement-a new journal was announced at this event-the Journal of Business Anthropology. And this is all very much embedded in organizational structures. It's Bang \& Olufsen, it's Royal Copenhagen Pottery, it's Hugo Boss; this is the real world of creativity, right? It's organizationally embedded-and what I kept seeing, in these ethnographies, is: there are power relations, right? There's the designer who's been designing successful products for thirty-five years, so senior management tends to trust this person. Then there are the new people who just got their MFA in industrial design so they haven't proven themselves yet. So absolutely there are power issues-some people's evaluative opinions count for more than others, if you're looking at evaluative practices, which was the theme of the conference.

But I sense you had a bigger question, and another way I could answer that is "why is it that people in power would want creativity?" And maybe they didn't want creativity for most of human history, let's say. I think, if you read the business press, you'll read that people in power, mainly management, politicians, etcetera, they talk as if creativity is very important. And this has been true throughout the world, right, not just in Canada and the United States. For at least ten years or so, we've been in a creative economy, we're an innovation economy, so it seems as if people in power are welcoming creativity, but maybe with your cultural studies hat you would say, "well, they probably don't really want creativity" or "they only want a certain kind of creativity." At least they want some creativity. So I view that as a good development. I think that compared to maybe fifty years ago, or sixty years ago, where-especially as an educator and education researcher, we had schools that did not teach people how to be creative. They taught rote memorization, and graduates went and got jobs in factories, and they did the same repetitive motion for forty years. So if you were in power, you didn't care if people were creative, and you didn't care if they'd learned how to be creative. I don't think that's the case anymore. I think people in power genuinely believe that we need everybody to be creative, even the people who might not have power right now, but maybe l'm overly optimistic and naïve.

ML: I guess maybe this question is more about the endgame of creativity. You talk about people in power being more receptive to creative agency within their organizations, but I wonder if that kind of creative agency, even though it's novel, is still directed to the same old corporate goals? And I wonder if those old corporate goals are reifying and reaffirming old power hierarchies both inside and outside of corporations?

\section{KS: Right, you know, I'm thinking about-}

ML: Basically l'm thinking about ways to negotiate the traditional goal of, you know, benefiting shareholders and making a profit, and the kinds of broader potential, emergent corporate goals that are more aligned with ideas about developing economically and environmentally sustainable practices, with breaking down systemic hierarchies-things like that. What can improvisation research in business kind of tell us about that?

KS: Well, I think it all requires creativity. I guess I would make the claim that creativity and innovation happens in a certain way. I feel like, as I said, I think the management community has come to a consensus about what organizations look like when they're good at fostering innovation. And I don't think that's only the case in for-profit focused organizations. I think that's true in non-profits, that's probably true in government organizations, although they mostly don't look like that, and we have a lot of pressing social problems around the world that require creativity and innovation, so I would look for the same sorts of fundamental human, social and organizational processes, whether the goal is making a profit, or whether the goal is solving a pressing social problem. And again, maybe that makes me naïve. As a social scientist I look for kinds of organizational structures and processes that result in innovation. I don't think it would change depending on the desired outcome. So then the question of "how do you design an organization so that a certain outcome is more likely than another," well, that's the challenge in general, of fostering the improvisational, emergent innovation in a way that aligns with organizational goals. So I guess I don't 
have the answer. And I could say something about social entrepreneurship, which, tends to also, I would say, follow similar innovation processes and organizational dynamics to for profit entrepreneurship. And yet it's directed at a desired social outcome.

ML: Well, one thing that intrigued and excited me about some of your work is the way that you talk about the value of diversity within the corporate setting, and the importance of diversity in creating what you call group flow. Maybe l'll let you talk about group flow, but l'm wondering how that element of diversity that you say is crucial to group flow might be one way in which an improvising business can integrate greater social, cultural, and class diversity within the work environment. And more generally, whether a corporation can or should model (or reflect) the constitution of a community.

KS: Ah, right, right. Well, it's in the name of the grant, right? Improvisation, Community, and Social Practice. It's a great question. My doctoral adviser Mihaly Csikszentmihalyi, with this hard to pronounce Hungarian name, he's famous for the concept of flow, and his book from 1990 called Flow: the Psychology of Optimal Experience, so it's a sort of study of when people get into peak experience states; it's very much related to research on intrinsic motivation and there's a lot of evidence that in the flow state, people are more creative. So there's the link between the flow and motivation research, and the creativity research. So in my 2007 book, Group Genius, I had a chapter called "Group Flow"-and the concept's really caught on, actually. And I was thinking, again, Mihaly Csikszentmihalyi is a psychologist and he's really focused on creative individuals. And his whole career, it's sort of a 1960s era personality psychology approach, whereas I wanted to look at group dynamics and it seemed to me that groups collectively get into a flow state, especially jazz ensembles, right? Improvised music ensembles. And there's a state of collective peak performance. And again, it doesn't always happen. Just like for individuals, you're not always in the flow state when you're doing something, but there are characteristics that are more likely to get you into a flow state. That's Mihaly Csikszentmihalyi's research.

So I came up with a list of ten characteristics that are more likely to result in a group being in this group flow state. And there's a sort of paradoxical opposition. One of the characteristics is familiarity. And again, this is research and organizational behaviour, not only my own research, that groups are more effective when they have some familiarity with each other. And anyone who plays in a jazz ensemble knows that you get better if you play with musicians more than once. So that familiarity is the case with musical creativity and also business teams. But also, another one of the ten characteristics is diversity. Right? Which, to some extent, seems like it might be opposed to familiarity, so that's the challenge: the research seems to suggest that it's not, it's a certain kind of diversity, right, we call it "cognitive diversity." It's not just having different coloured skin, let's say, or speaking a-maybe speaking a different language, but as long as those things result in your cognitive make-up being different, well that's what, from the psychological perspective, results in new ideas, or good new ideas, is bringing together diverse bodies of knowledge. So that research in cognitive diversity makes sense to me because what it results in, if you get teams with cognitive diversity, they're more likely to bump against each other these distant ideas or these more remote ideas. So, for example, a lot of organizations have experimented with cross-functional teams, where you bring someone from marketing, and someone from engineering, and someone from manufacturing. Well, then there's a problem because a lot of times they don't know how to talk to each other. Because they speak different languages and they have different value systems and different epistemology. So, it doesn't work just doing that; you have to also have some way of fostering the communication between them.

There's this term that I use, that I stole from IDEO, which is a product design firm in the San Francisco Bay Area. They talk about the type of people they want to hire, and they say they want to hire "T" shaped people. And we want someone who has a deep body of expertise in one narrow area, because you need that to be creative, we also know that. But the top part of the "T" is we need you to be a dilettante in a lot of different areas. So that allows you to communicate with people that are different from you. So yeah, I guess I would say if you want to foster diversity and use it to benefit the success of a team or an organization, you have to, of course, bring something to the table that's different from everybody else, but also have that ability to sort of at least envision yourself in such a way that you can talk to someone that's different from you. And then you can bring together and get the benefits of that cognitive diversity.

ML: Great. No, that makes sense. And, I guess, how might we frame that in terms of an ethical business design? How can business management help model or reflect the kind of community that many of us aspire to?

KS: Right. The sort of Habermasian communication norms, or communicative action.

ML: Right. 
KS: Sure. I aspire to that. So yeah, I think it's quite similar, right? In a way. So, it's that sort of paradoxical combination of familiarity and trust, and yet diverse bodies of knowledge. So, yeah, it's easy to get trust and familiarity if everybody's exactly like you, but then you don't get any new ideas, you don't get any innovation.

ML: Right. Still thinking about these ideas about breaking down hierarchies, in Explaining Creativity, you spend a lot of time deconstructing mythologies about creativity and one of your focal points is the idea of creativity and innovation as being a very individualist phenomenon, related to ideas and discourses about individual genius. And of course there's been a great deal of ink spilled in cultural studies about deconstructing individual genius, mostly along gender lines. The mouthful buzzword is "phallologocentrism"-basically how individual genius has been traditionally aligned with white masculinist domains. So I'm wondering about how, by decentering these ideas of individualist genius in a management setting, how might we also be able to decentre concomitant ideas about gender and race?

KS: Oh yeah, it's a very rich question, and of course I'm thinking of all sorts of ways-you know, and I talk about this briefly in Explaining Creativity. Even though l'm a psychologist, I feel like I had to learn something about other disciplines to avoid, sort of, ignoring obvious things that would seem obvious to someone in another field, so I associate this with a sort of Roland Barthes and the death of the author sort of position, starting in, what, 1969 or early 1970, this claim that the author doesn't really exist. Barthes calls him the "inscriber" or something, anyway it's not my area of expertise, but as I understand it, this is not a new idea in literary theory. That the author is a myth. I repeat the claim and I'm doing something similar in my book about group genius: I'm claiming that the solitary creator is a myth. And actually, I make that claim throughout history. I don't think we had a distant time in the past when individuals worked alone, male individuals or whatever gender, and generated products. I think it's a mythical view projected on a certain image of what the author was. So I guess maybe l'm agreeing with Roland Barthes, perhaps to some extent. When it comes to the individual creator, I don't think there ever was a solitary creator.

So, nowadays, more so than ever, collaboration is even more important, but in Group Genius, I go back and l've looked at the history of invention in a couple of different areas-I talk about the invention of the telegraph, which in the United States we learn it was Samuel Morse who invented the telegraph. And I read a whole book, a wonderful book by Tom Standage-it's called The Victorian Internet, and the telegraph is the Victorian Internet. It wasn't invented by any one person. There was a complicated stream of contributions over time, just like the improvisations l've been describing. Over 14 years, by the way. And the first telegraph was in England by a totally different group of researchers, not even Samuel Morse. Charles Darwin with the Theory of Evolution by natural selection, you know, he didn't think it up while he was spending five years on the Beagle in the Galapagos; he was back in Cambridge, I believe, for nine more years collaborating, interacting with people.

So to some extent I think maybe the feminist theorists are sort of buying into the myth, to some extent, that there ever was this male solitary genius. I don't think that was the case, but we have these mythical views perhaps. Maybe it's associated with certain reigning ideologies of gender, I don't know, but it's certainly a belief in Western countries, certainly the United States, [that] we have this very individualist mindset, and that leads us to false beliefs about the creator being the genius flash of insight, being alone from other people you're more likely to have a flash of insight; you're always fighting against convention and rejecting everything that's come before. Or, the belief that it's better if you're not educated in the area because you're going to be constrained by the habitual way of doing things. All of these are myths, and that's not really what happens in the history of invention. So, it's something about a cultural ideology of the individual. I've never thought of it being associated with gender, but perhaps.

ML: Well, I guess my point is partly that I think your work is very aligned with feminist theory in that respect, in that I think most feminist theorists would argue that there is a distinction between historical fact and historical narrative. So, I think most feminist theorists would argue that historical fact is that individual genius is a myth, but the historical narrative has been such that it's constructed a notion and discourse of individual genius aligned with masculinity. So for instance, if you were to wander around, you know, a museum of invention or innovation, or as a music historian, if you were to flip through a music history textbook, you would see the same faces again and again. You know, you'd see a room full of old dead white men.

KS: Right! And I have a deck of cards. 52 cards. It's called the invention card deck, and each one has a picture of an inventor.

ML: Right!

KS: And are any of them women? Maybe a couple?

ML: Yeah. And one of the things that is so exciting to me about your collaborative improvisatory model of innovation is the way that it does destabilize that deck of cards. 
KS: Right, right. It challenges the same ideology that feminist theories are challenging. But is the claim that women are more likely to collaborate? Or that this is a more natural tendency.

ML: I've heard that elsewhere. That isn't what I was thinking of in terms of this question, but I had read that. I'm reluctant to come down and say yes, women are genetically pre-disposed to collaborating-l'm a little bit skeptical about biological essentialism. My question is more about discourse and narrative than it is about biology, and basically how does an innovative and collaborative model for creativity invite us to narrativize the history of invention in a way that includes more kinds of people.

KS: Right. Absolutely. So, that's interesting. I'm glad to hear that it's compatible. Certainly as l've said, I know it's compatible with certain strands of French theory, literary theory, I guess out-of-fashion a bit, but certainly there's a truth to that. In Explaining Creativity, I have a chapter on scientific creativity. There are some fascinating studies by people who go into scientific laboratories, and study the organizational dynamic in a scientific laboratory that lead to the senior scientists getting more credit for the collective products of the lab than is really warranted. And so we always have-many of us in academia think that it's because of these selfish overlords running the lab that are stealing all the credit. Well, it turns out that there are incentives for the people in the lab to work to have that person gather more credit. This is just fascinating and it sort of opened my eyes when I read this. For example, it helps you get better postdocs if your senior scientist is more famous, or your reputation is enhanced indirectly. There are all sorts of human organizational processes, I suppose, that result in the perpetuation of this myth of the solitary genius. And it's not necessarily because someone's being selfish, but it is power dynamics at some level, I suppose.

ML: I think it's systemic power dynamics. It continues to prop up the same sort of myth in which we're deeply invested for a variety of reasons - financial and cultural - in terms of the way that we understand ourselves in the world. As you said, it's a great deal of investment in that idea of how invention and creativity come about.

KS: I think, well, just again, I'll say, I think it's human nature, it's a human organizational form. I'm often speaking in contexts where people are talking about the Internet—and you've probably all seen books—the Internet is enabling a new form of mass collaboration. Of course, Wikinomics, famously associated with Canada, right? But many other books argue that we have this new mass collaboration because of the Internet. I don't think it's a new human organizational form. I think we've been doing this collaborative-l called it a collaborative web-and we've been doing it forever, or certainly at least since modernism and the nineteenth century, but the Internet makes everything a lot faster, I think, but it's possible for us to do it because of the pre-existing organizational forms. It's just who we are as human beings, so, no I would not agree that, you know, women are more likely to collaborate, or I don't agree that poor people are better at making jazz because they're oppressed. I mean, there are all sorts of these essentialist ideologies out there, but I think it's just who we are as human beings. I think we all have it.

ML: Right. Yeah, we should shortly open up the floor for questions, but I did have one more question on my list that I really wanted to get to. I had a list of ten questions here, and somehow I thought I was going to be able to get through all of them in forty-five minutes and we're just now moving into question three. [Laughter.] In any case, in debunking these cultural myths about creative genius, one thing that you don't really talk about, which again is one thing in cultural studies we talk about a lot, are the politics and ethics that are associated with creativity. Specifically, I'm thinking about oppositional politics. Improvised music, jazz in particular, has historically been the province of socially marginalized communities, especially lower and middle-class African Americans. So basically l'm wondering if there is a link between creativity and the kind of oppositional politics that are practiced by many of these individuals, or conversely, if you consider that to be a sort of social coincidence.

KS: Right, right. Okay! So, yeah, I have maybe two answers. One is, so I just said poor people aren't better at playing jazz. Well, in the-there's a history behind it, right?-in the mid-1990s I did some research cross-culturally, in the ethnomusicological literature and also linguistic anthropologists who study ritualized verbal performance. And I discovered an interesting pattern. That what I was looking at was fundamentally this dimension from more improvised, to what I call more ritualized. In the West, we might call it composed, but in many of these cultures they don't have notational forms, so you can't refer to a composed genre, but certainly some genres are more likely to be the same when they're repeated over time and they're more likely to be resistant to change, so I call those more ritualized. More improvisational genres, well, it's what we all understand by improvisation. And many of the world's cultures have multiple performance genres that fall at different locations on the spectrum-more improvised to more ritualized. And I identified nine contrasting dimensions - they are contrasts that are associated with this spectrum, and the one that I found most interesting in this context was the cultural valuation. In every culture I looked at that had multiple genres of improvisation-multiple genres of performance at different places on the spectrum-the most highly culturally valued was always the most ritualized. And the one that was the least culturally valued was always the more improvised one. And I thought it was fascinating that that held true around the world and maybe there's sort of a human tendency to place a higher cultural valuation on more highly ritualized forms. What I mean is, if it's a more 
important occasion that's being marked, it'll be a ritualized one. And further-when a tape recorder is introduced to the culture for the very first time, say in the 1970s or 1980s, they would start making tapes of the more ritualized performance genres, but they would never think of making tapes of the more improvised ones. There's all sorts of evidence that the more ritualized genres are more highly valued. So that probably is related to, you know, common observation that it tends to be the dispossessed or the disadvantaged that engage in improvisational forms. Maybe the inverse is true because of the high cultural valuation of the more ritualized genres. They tend to be reserved for the elite, perhaps, or the people in power. So that's interesting. I don't have any more to say other than to make that observation. I don't think it's-so it's not an essentialist claim, but still it's a way of explaining something that we've all seen, perhaps.

ML: A cultural anthropologist like Victor Turner, or other people who have worked on ritual, I think, would argue that one of the functions of ritual is to reaffirm power dynamics, essentially. So part of the reason that you repeat the same processes again and again and again and again is so there's a sense of continuity of things in the existing power structure. Evidently, improvisation is, for exactly that reason, less conducive to ritual because it's different every time. I'm thinking about trying to map that kind of analysis of the cultural function of ritual onto a business scenario, in terms of a ritualistic repetitive kind of business management associated with Taylorism or Ford's mass production. Basically, you know, small tasks that are repeated again and again and again.

KS: Yeah, so, the good news is, I think things are changing. I think that we have now innovative organizations that welcome the sort of productive form of argumentation, that welcome the individual who won't accept unquestioningly what senior management says. Now, that's not the story for lots of people working in corporate America, but I think we have a movement towards - at least in certain sectors of the economy, certain, maybe more enlightened organizations - a recognition on the parts of new management that we need these kinds of individuals that you call oppositional, I don't know, maybe l'd think of a different word-certainly not "yes men," or "yes people." "Yes people" doesn't sound right. [Laughing:] Women aren't "yes women," it's only men who are. [Laughter.] Right, so I think there's a recognition. I guess maybe I'm just an optimistic guy, but it was a lot worse before, fifty years ago. It's a lot better now. And I think it's because senior management has realized what I think myself and my colleagues have discovered about innovation. And if you're not going to tolerate any dissenting voices, that kind of organization doesn't generate new ideas. I mean, we're teaching them that in our MBA programs, so I hope they're learning something.

ML: Well, I've been monopolizing Keith, for I guess about a half an hour now, so I guess we should probably open the floor for questions.

Auditor \#1: Keith, thank you. This was really interesting. You were talking about the Internet, and how that's increased-sped up life. So, that interchange or exchange between people is much quicker. I know that [Jerome] Bruner said "the enemy of reflection is the breakneck pace." I sometimes find myself as I watch my kids, you know, twittering and whatever away, I think about that construct of time a lot, and I'm wondering whether you could relate time to-and time needed for reflection-to collaboration or innovation, and maybe even using the jazz metaphor? I'm not a musician myself, but I find the metaphor absolutely fascinating.

KS: Right, right. So, raise your hand if you're twittering or blogging right now. We've got one person! [Laughter.] See, there you go! But you'll reflect afterwards. I think it's true. When you study-when I study, when my colleagues study - the creative process, one stage that we talk about is what we call incubation. Or you might call it "time off," right? And it seems like the sort of insight moments, when something surprising occurs to you, often don't come when you're engaged in the depth of hard work on a problem, but it's when you take some time off, and you're doing something else. This is just something we observed from interviews with exceptional creators. A lot of the time it'll be some kind of physical activity. So it might be gardening or exercising, or it might be fixing a meal. So absolutely, having time in your day, and to take time off, and I think it's an important part of the creative process, because that's when you're more likely to have these ideas pop up. And we have all sorts of experimental evidence in the laboratory evaluating whether or not there is an incubation effect with controlled experimental designs, and indeed, there is. So, you know, you could control, right, you could have people take time off from a task and do something else, or have them-so we designed the experiment to control or adjust for having extra time, right? And yeah, it seems to be that taking time off makes those ideas more likely to emerge. Is that what you're getting at by...?

Auditor \#1: Yeah, I'm just wondering in terms of, again, not being a musician-l'm really curious whether that jazz metaphor is useful, because when I think about a piece of jazz music, that say is improvisational, I think "how does that construct of time work for the musician individually and as a group?" And whether that's-there's anything to be learned from considering that. 
KS: Oh, that's a good point! Right, because you're in the moment, and it's moving ahead and you can't stop and reflect. While, you're reflecting while you're playing, but you're not stopping and exercising or gardening or something. [Laughter.] So it can't be in the moment. It has to be through the doing. [Thinking, nodding.] So, yeah, I guess we have a lot of other musicians here. It happens when you're not performing and you're not performing most of the day, so that I think would be your reflection time. It doesn't mean you have to be doing nothing. So, one common practice of exceptional creators is that they tend to have multiple projects underway simultaneously, and if they get to a stump or an impasse in one project, they can start working on another project. And working on another project still gives you incubation on the first one, so it doesn't mean you have to sit and stare at the wall, right? You can go do something else productive and if-if you had multiple things underway. So yeah! If you're performing five hours one night, the next day you go to your day job, like most jazz musicians, so maybe that day job could actually give you that incubation that you need.

Auditor \#2: So, I have a question for you about the University as the organization and I was intrigued to hear that some of your work's been around teaching and marketing, and the classroom, and of course we're hearing a lot of challenge to the university's academe today in terms of, you know, questioning, to what extent, we're fulfilling our purpose in terms of society's needs. And I just wonder, you know, we look all about decision-making, innovation, creativity within the university or what kind of suggestions might you make to university administration when we have faculty that many see themselves in very sort of, individualistic ways, and how do we build a faculty-how do we turn the university into musicians. [Laughter.]

KS: Oh, it's a good question, and l've quite often been invited to give keynotes to university administrations. And, oh, about a year ago, it was Oklahoma Association of Community Colleges, which was all the deans and chancellors, and usually when I'm speaking to universities I describe what innovative organizations look like as the bulk of my talk, and then at the end, or maybe during question and answer, I say, "well, you probably all noticed during my talk that universities don't look anything like this." Right? They have really rigid unit boundaries, very rarely is there crossdisciplinary collaboration, although we all know that's where lots of the innovation happens. We don't have a sort of organizational dynamic where ideas build over time, and things emerge spontaneously. Well, I guess l'd qualify that. Academic disciplines? I think they are quite innovative. They are designed like collaborative [groups]. So, in a discipline, you will interact with people around the country and around the world-it's just natural to you, going to conferences, you're emailing people, you're on these mailing lists for everybody in your discipline, so knowledge is flowing around in the discipline all the time. I think where we don't have innovation at the university is at the administrative level, the sort of organizational structures of the university is quite stable. And I actually see a lot of innovation happening, not at the high status centre. It seems to be happening in community colleges, which in the US-I don't know if you use the same term in Canada, you get a two-year degree instead of a four-year degree. And in terms of the big status scale of universities, they're way down at the bottom in terms of status. People don't do research, they teach five classes at a time, and they tend to get students who are not as high-scoring as at the fouryear university. But they're innovating like crazy. For-profit institutions-a lot of innovation. But in universities like mine, Washington University, a top research university, we're very conservative. We won't do anything unless Harvard or Stanford did it first, for ten years, and proved that it worked. And I'm frustrated by this. By the way, Stanford, I think, is probably the most innovative institution, and it's because there's a culture there where new organizational units can pop up, so I don't know. It's a depressing answer perhaps, sorry. It can happen.

Auditor \#2: You said you were an optimist. [Laughter.]

KS: You can do it! Maybe at Guelph. I don't know Guelph, maybe you're one of the innovative ones!

Auditor \#3: Okay. I have one quick comment and then a question that l'll preface it by saying you're welcome to go: "great question, next question." Just on the collaboration and women, in terms of the research you did, [it] was very interesting to me, that about $85 \%$ of all the-depending on who's meta-analysis you read-say that women managers, or women in organizations, not just managers, are more collaborative, more inclusive, etc. But if you look at those studies, the other issue you brought up in the beginning on power, virtually every study ignores that issue, and if you start looking at women who are in the most senior levels of organizations, there are absolutely no studies to show that women are more collaborative or less collaborative, more inclusive. So, I think like a lot of the other studies, where sociologists have helped us understand that structure, and especially stuff coming out of North America, that left aside power structures, a little bit in management studies, [...] but that would be easy. My question is: being an expert on collaboration in organizations, that have purposes, and having observed a lot of them, and being an optimist, and given the country you're currently living in, are there any recommendations whatsoever that you could give to the US Congress assuming that you were invited in, to try and get them collaborating for the greater good of the country. [Laughter.] 
KS: Ah, well. l'll interpret that as two different questions. One is: what should a government do to best foster innovation throughout a country? So, I guess, focusing too much on the central government I would view as a mistake, because of my own belief that innovation emerges from the bottom up. So, and this is perhaps the fundamental national difference between the US and certainly my colleagues in European countries where they talk about national innovation systems - and there is very much what I perceive as a top-down view of "we're not as innovative as the United States," and "here's what our government should do to make everybody more innovative." And I feel like they're sort of missing the key point, but it could just be a sort of different in national political culture, to what extent you believe in central government as providing solutions versus allowing things to emerge from the bottom up. So the bottom-up emergence thing I think is quite compatible with the US, sort of, political and economic culture, which also has various negative, unfortunate side effects, like higher rates of poverty. But, in terms of the political class, I-what can I say other than I think everybody is a rational actor, frankly, including the people in Congress. So I don't blame Congress, I blame all of us. Sorry. I guess that doesn't sound like an optimist. It's my fellow citizens, yeah, it's not the politicians.

Auditor \#3: Well, I asked the easier question.

KS: [Picking up watch, joking:] But we're over time. [Laughter.] If you want to leave with the optimistic note, yeah, there are all sorts of depressing things going on and all sorts of collaborations that are ineffective. But I do think that collectively, as the United States and also internationally, we're all becoming more innovative and more creative, and I think leaders around the world are becoming not only tolerant, but seeking out creativity and innovation and dissent, to some extent. So that's why l'm optimistic. Things are getting better. People in power are starting to realize it's in their own best interest to do things that we all think are done. So that's why l'm an optimist. So, thank you.

\section{[Applause]}

\section{Notes}

1 "Dr. R. Keith Sawyer, the Morgan Distinguished Professor in Educational Innovations at the University of North Carolina, Chapel Hill, studies creativity, learning, and collaboration. After receiving his computer science degree from MIT in 1982, he began his career with a two-year stint designing videogames for Atari. His titles included Food Fight, Neon, and Magician. From 1984 to 1990, he was a principal at Kenan Systems Corporation, where he worked as a management consultant on innovative technologies. His clients included Citicorp, AT\&T, and U.S. West. In 1990, Dr. Sawyer began his doctoral studies in psychology [at the University of Chicago], where he studied creativity with Dr. Mihaly Csikszentmihalyi (author of best selling books such as Flow and Creativity). Since receiving his Ph.D. in 1994, he has dedicated his career to research on creativity, collaboration, and learning. He has been a jazz pianist for over 30 years, and spent several years playing piano with Chicago improv theater groups. Dr. Sawyer has published 12 books and over 80 scientific articles. His research has been featured on CNN, Fox News, TIME, New York Times, Wall Street Journal, NPR, and other media. A popular speaker, he lectures to corporations, associations, and universities around the world on creativity and innovation" (Sawyer).

\section{Works Cited}

Sawyer, Keith R. "Dr. Keith R. Sawyer: Brief Biography.” keithsawyer.wordpress. 2008. Web. 16 Jul. 2013. $<$ http://www.artsci.wustl.edu/ ksawyer/> 